\title{
Grande y gruesa pequeña literatura
}

\author{
Olalla Hernández Ranz \\ Universitat Autònoma de Barcelona, Barcelona, España
}

(Artículo recibido el 21 de noviembre de 2011; versión final recibida el 25 de enero de 2012)

\begin{abstract}
A partir del estudio de BIG FAT LITTLE LIT, una recopilación de historietas de diferentes autores concebidas para niños y editada en Estados Unidos por los expertos Francoise Mouly y Art Spiegelman, la presente investigación reflexiona sobre la forma en que se expresa el cómic infantil a un nivel intratextual. Inscrita dentro del campo de estudio de la narratología, el trabajo analiza el tiempo narrativo de historia y discurso de la historieta infantil, con el objetivo de obtener conclusiones que abran nuevas vías de investigación que incentiven la creación de este medio de expresión en nuestro país.
\end{abstract}

\section{Una introducción a la narratología del cómic infantil a través del tiempo}

Según el especialista Seymour Chatman (1980, 1990), el estudio de la narrativa es hoy tan popular que los franceses la han honrado con el término narratologie (narratología) (Chatman, 1980:121). La narrativa estudia la organización de un texto y cómo se articulan sus elementos; la narratología investiga, además, qué tienen en común los textos narrativos y qué los diferencia de otros textos que no lo son. Con todo, aunque los distinga la forma en la que se materializan, es decir, aunque se trate de una novela, una obra de teatro, una película o una historieta, la obra narrativa posee siempre una estructura espacio-temporal a partir de la cual se organiza la historia. Ese tiempo narrativo al que nos referimos es un elemento estructural imprescindible, que proporciona soporte a la historia y que es común en todas sus realizaciones.

El tiempo es el único elemento intratextual que existe en el espacio de la historia (lo que se cuenta) y en el del discurso (cómo se cuenta la historia); el tiempo conecta ambos espacios. Como señala Chatman (1980), aunque el concepto de tiempo esté presente en todos los textos, es decir, aunque suponga un periodo de tiempo leer un ensayo, una sentencia o un sermón, la estructura interna de los textos no-narrativos no es temporal sino lógica, de modo que el orden temporal de su discurso es irrelevante. Sin embargo, el desarrollo del elemento temporal de historia y discurso es principal en los textos narrativos, por lo que cualquier texto narrativo es transferible a otro, 
precisamente, por contener esta doble estructura que le permite comunicarse (Chatman, 1980).

El presente trabajo, por tanto, se centra en el análisis de la estructura temporal de un corpus narrativo concreto, con la intención de extraer características y recursos propios del medio estudiado en su producción infantil. El estudio del elemento temporal parece clave, en este caso, para conocer la manera en que el cómic construye sus historias e, incluso, los niveles de sofisticación posibles que aún están por explorar en la producción autóctona concebida para niños.

\section{El cómic, un medio de expresión narrativo que nos interesa}

Si bien han sido muchos los intentos de definir el medio, todavía hoy parece una cuestión sin resolver. Esto se debe, según el investigador Thierry Groensteen (2007), a que se ha tratado, en todos los casos, de extraer la esencia de un sistema complejo, cuyos mecanismos y forma de expresión varían de una obra a otra. En dichos intentos, al tratar de extraerse la esencia, varias características importantes quedan excluidas en una definición que resulta a menudo incompleta (Groensteen, 2007).

De modo que aunque afirmemos que el cómic se compone de imágenes organizadas en secuencia (Kunzle, 1990; Muro, 2004; Eisner, 1996), imágenes yuxtapuestas en secuencia (McCloud, 2005; Guiral, 2007) -donde lo icónico prevalece a la palabra (Kunzle, 1990)-; que el cómic se sirve de dispositivos para expresarse como la viñeta, el panel o las cajas que recogen esas palabras mínimas (Harvey, 2011) y que de la interacción de ambos códigos surge una historia, que es a la vez moral y tópica (Kunzle, 1990); o, como apunta el mismo Groensteen (2007), aunque identifiquemos al cómic como un lenguaje que surge de la combinación de diferentes códigos motivados, en gran medida, por lo que él ha venido a denominar solidaridad icónica (iconic solidarity), es decir, donde sus componentes visuales se encuentran en estrecha conexión de significación para lograr el acto narrativo, siempre encontraremos opiniones encontradas y apuntes que completen las características de un medio de difícil, si no imposible, definición.

Dejando entonces a un lado las esencias, opinamos que el cómic es un medio de expresión siempre narrativo que se desarrolla tanto en el plano de la ficción como en el de la no ficción, y que requiere de la imagen secuenciada en viñetas para lograr su fin en hoja o pantalla. Creemos, además, que su soporte, forma y contenido han tenido en 
cuenta el contexto sociocultural al que pertenecía y que, si bien no todo cómic se lee impreso, la posibilidad de reproducción y de accesibilidad para el lector es condición sine qua non.

Así, el cómic nos interesa porque, a través de la narración gráfica, propone al lector una experiencia a la vez literaria y artística que completa, de algún modo y por la propia naturaleza del medio, su educación estética y ficcional.

\section{Corpus de estudio, Big Fat Little Lit}

El corpus de estudio consta de una única obra, Big Fat Little Lit (Mouly, 2006), un volumen que compila 33 historietas infantiles y reúne a algunos de los mejores autores de cómic europeos y norteamericanos. Little Lit forma parte de un proyecto iniciado por la directora de arte del New Yorker Francoise Mouly en 2000 y nace influido por el éxito de la revista Raw, que también dirigió durante años, una revista de cómics independiente y destinada a lectores adultos que supone un giro conceptual a lo que se venía haciendo en las grandes editoriales. Mouly traslada esta idea a Little Lit para crear un proyecto similar en cuanto a su propuesta formal y de contenido, pero concebido para niños. Estamos estudiando, por tanto, un ejemplo modélico de narración gráfica dentro de la producción de cómics infantiles que nos permite conocer las posibilidades de creación con las que cuenta el historietista a la hora de contar en clave de cómic.

\section{Elemento analizado, el tiempo narrativo}

Gérard Genette (1972, 1998), uno de los estudiosos más relevantes de los géneros literarios y el texto, el lenguaje, su morfología, orígenes y mecanismos constitutivos, escribe entre 1966 y 1972 Figures, tres volúmenes de estudio sobre narratología que conforman una de las referencias más importantes en cuanto al estudio del tiempo narrativo.

El estudio de las distorsiones temporales del autor francés aplicado al cómic nos proporciona las claves no sólo para investigar de qué manera el texto gráfico de la historieta emula el paso del tiempo, sino para observar los niveles de sofisticación que alcanza en su enunciación y desarrollo. 
El análisis del elemento temporal muestra cómo el cómic tiene una naturaleza fragmentaria en su composición gráfica y verbal, aglutinadora de lenguajes y medios de expresión con los que convive en una misma época.

A pesar de que en Figures Genette (1972) plantea un modelo tripartito que señala las interrelaciones entre relato, historia y narración, el modelo que se sigue en este trabajo defiende una estructura dual donde se analizan las alteraciones que se presentan de acuerdo a las relaciones entre el Tiempo de la Historia (TH) y el Tiempo del Relato o Discurso (TD).

Las alteraciones que se producen entre el TH y el TD están agrupadas en tres tipos diferentes: distorsiones de orden, de velocidad y de frecuencia.

\section{Distorsiones de Orden}

Las distorsiones de orden ${ }^{1}$ tienen que ver con una decisión de alterar la secuencia cronológica de la historia. Estas alteraciones suponen anacronías entre el tiempo de la historia y el tiempo del discurso en relación a un tiempo base. Dichas anacronías pueden ser de dos tipos, analepsis y prolepsis.

1) La analepsis consiste en un salto hacia el pasado en el tiempo del discurso, siempre en relación a un tiempo base marcado por el tiempo de la historia.

Encontramos este tipo de anacronías en varios de los relatos gráficos que conforman el corpus estudiado. Uno de ellos es These Cats Today!, historieta creada y dibujada por Kim Deitch, una de las figuras más representativas del Comix Underground que se desarrolló en Norteamérica a finales de los 60. Influido por la psicodelia, Deitch rompe, por un lado, con los estereotipos que construyen la imagen “adecuada” para la narrativa infantil y, por otro, propone un desafío al lector: ordenar los tiempos con los que juega la página. 

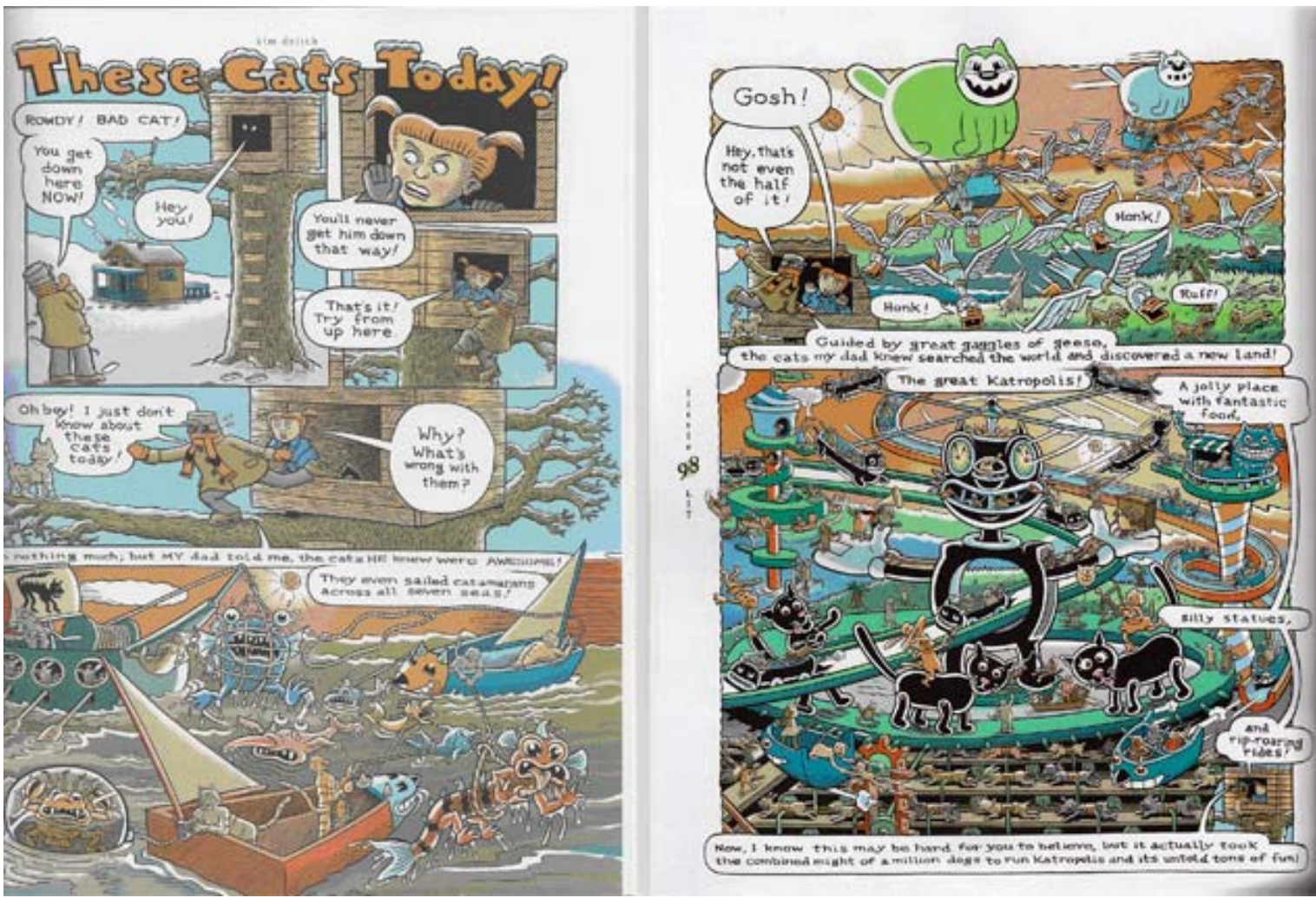

Figura 1. These Cats Today!

En la doble página, una niña ayuda a un misterioso personaje a recuperar el gato que se ha subido a la rama de un árbol en el que ella tiene su casa de madera. Cuando el personaje le dice a la niña que no reconoce al gato hoy, ella le pregunta por qué. En ese momento, el personaje le relata las razones por las que no le reconoce, recordando un cuento sobre gatos que solía contarle su padre. La última viñeta de la primera página y las que componen la segunda página al completo reconstruyen ese relato pasado en la memoria del personaje. Para marcar la diferencia, Deitch recurre a una estética surreal, distinta de la elegida para el tiempo base, en cuyo estilo se aprecia la influencia de la psicodelia que recibiría el autor a finales de los años sesenta.

En este ejemplo, como en otros, es el narrador-personaje quien da paso a la anacronía, la justifica y la anuncia en su bocadillo y avisa al lector y le sitúa en la metahistoria. Esta anacronía da paso a una segunda historia dentro de lo que llamaríamos historia marco o primera que contienen su propio orden temporal. Tras el anuncio del personaje, el lector observará un cambio de estilo en el dibujo y en la propia viñeta, que adopta forma de nube, distinta de las que contiene a la historia marco.

2) La prolepsis es una alteración en el orden temporal del discurso que implica una anticipación de sucesos que tienen lugar en la historia en orden cronológico. 
Veamos estas ideas con un ejemplo. Trapped in a Comic Book (Atrapado en un cómic) de Jules Feiffer es una historieta de seis páginas en la que un niño que ha ido a visitar con su clase el estudio de un dibujante de cómics dialoga con él sobre su obra. El niño, que no siente el más mínimo interés por los cómics de superhéroes, le pide al autor que cuente otro tipo de historias. El autor, en cambio, le sugiere que le dé una oportunidad a la lectura de la obra que en ese momento está dibujando. Para apreciar la historia, le pide al niño que se acerque a la página y, cuando el niño lo hace, queda atrapado en su interior, formando, a partir de entonces y literalmente, parte de ella.
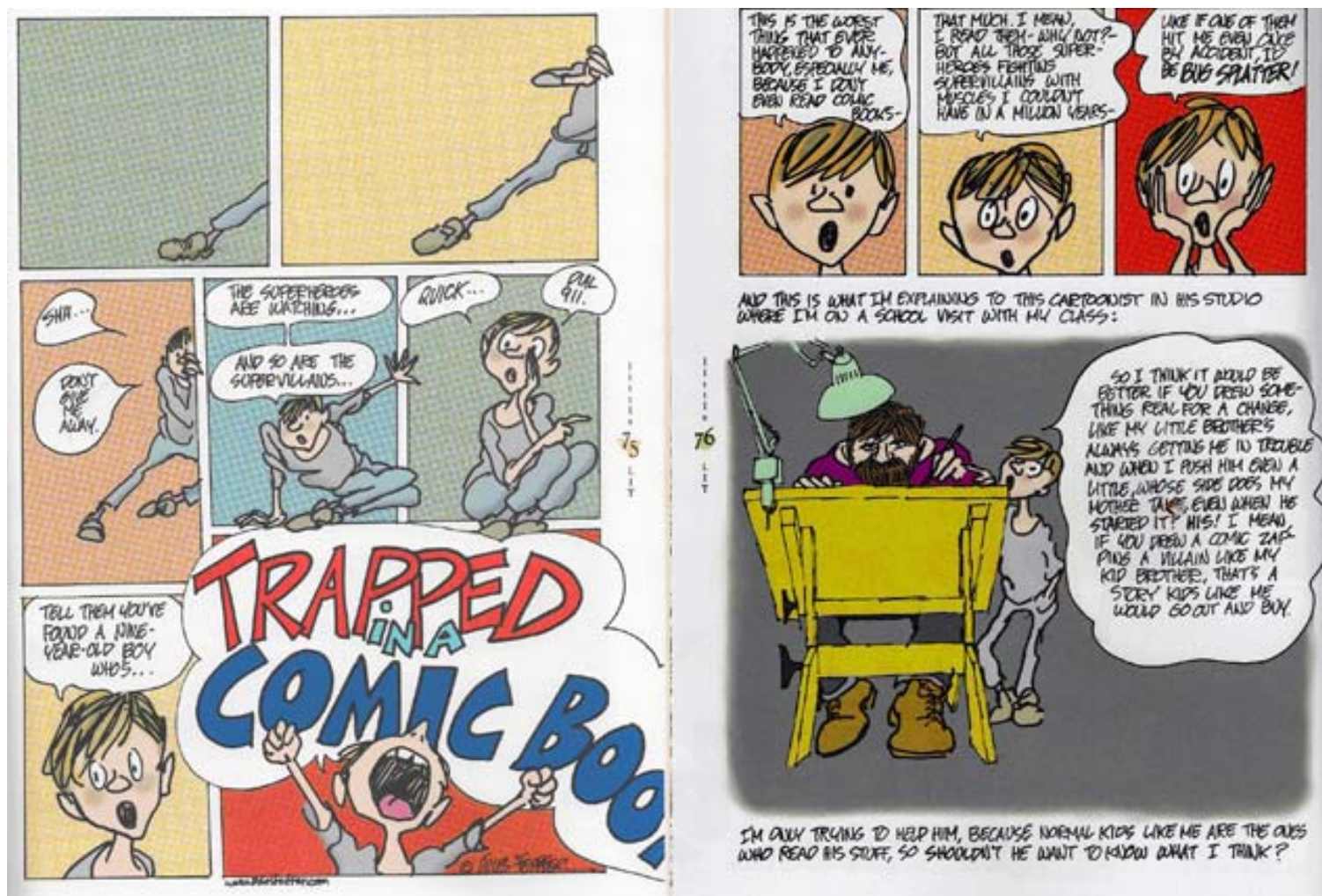

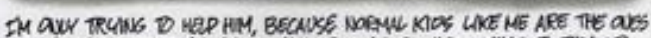

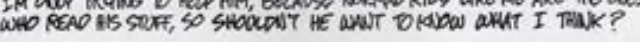

Figura 2. Trapped in a Comic Book

En una primera lectura, diríamos que el tiempo de la historia se extiende durante las horas que dura la visita de la clase al estudio del dibujante. Sin embargo, cuando observamos el tiempo del discurso, al tratar de analizar la forma en la que el orden temporal de la historia se dispone sobre la página, vemos que la narración da comienzo (Pág. 75) cuando el niño ya está dentro del cómic. De esta forma, el lector asiste, ya en la primera página, a una breve pero intensa anacronía que, tras el título, le llevará al inicio del relato gráfico más tradicional, enmarcado en una secuencia temporal lineal al uso. La prolepsis que da comienzo antes de la historia supone una alteración en el orden temporal e implica la anticipación de un suceso en relación a los que se narran en el 
tiempo base. Este recurso formal se emplea para dotar al título del cómic de carga emotiva y de misterio y como efectivo reclamo al lector.

Sin embargo, las distorsiones que tienen lugar entre historia y discurso suelen ser recursos puntuales; por lo general, en la mayoría de los ejemplos analizados, el tiempo transcurre en escenas de manera cronológica y el cómic lo expresa con las características de sus propios códigos.

El orden temporal lineal también es una condición enunciativa que continúa siendo muy respetada en la narrativa actual. Las obras sólo incluyen anacronías cuando estas derivan de la gestión de las complicaciones estructurales más corrientes. Por ejemplo, cuando se necesita retroceder para explicar escenas transcurridas en un tiempo simultáneo a las que se acaban de contar es un recurso frecuente. Tanta fidelidad al orden temporal lineal obedece a la idea de que los cambios temporales son difíciles de seguir, presupuesto muy asumido por la narrativa infantil y juvenil, tal como se ha visto en su resistencia a usar escenarios narrativos propios del tiempo pasado o futuro. (Colomer, 1998:267)

\section{Distorsiones de Velocidad (o Duración)}

Las distorsiones de velocidad ${ }^{2}$ tienen como fin crear una ilusión de celeridad o pausa en la acción de la historia. Este recurso permite al autor que el narrador o la imagen narrativa presenten sucesos que han acontecido durante toda una vida en un solo párrafo o en una secuencia breve de viñetas; pero también, si la acción lo requiere, pueden crear expectativa o misterio, detallando minuciosamente a lo largo de varias páginas, didascalias, bocadillos y viñetas un gesto que tuvo lugar en un sólo instante.

Para analizar esta distorsión, aplicamos el modelo de Gérard Genette que observa la relación entre TH y TD, comparando el lapso temporal al que alude la historia y el espacio físico que ocupa dentro de la página. Este tipo de discrepancia entre la velocidad del TH y el TD, también según Genette, da lugar a cuatro clases de alteraciones de duración: escena, pausa, resumen y elipsis.

Escena: Una escena es cada parte de la narración que transcurre en un mismo lapso espacio-temporal. En el momento en que exista una ruptura temporal o espacial, nos encontraremos frente a otra escena. Por lo tanto, en la escena el tiempo de la historia y el del discurso coinciden.

Una escena estaría compuesta, por ejemplo en el caso de Trapped in a Comicbook, por las siete viñetas que preceden al título de la historieta, donde se comparte tiempo cronológico y un espacio que cambia en la página contigua. 
En cambio, una secuencia es un conjunto de escenas que conforman una unidad dramática con planteamiento, nudo y desenlace. Dentro de una secuencia suele haber rupturas temporales o espaciales, aunque, en ocasiones, ésta puede constar de una única escena.

Pausa: La pausa es la forma máxima de desaceleración. En estos casos, como en el ejemplo que vemos a continuación, la historia se detiene por completo.

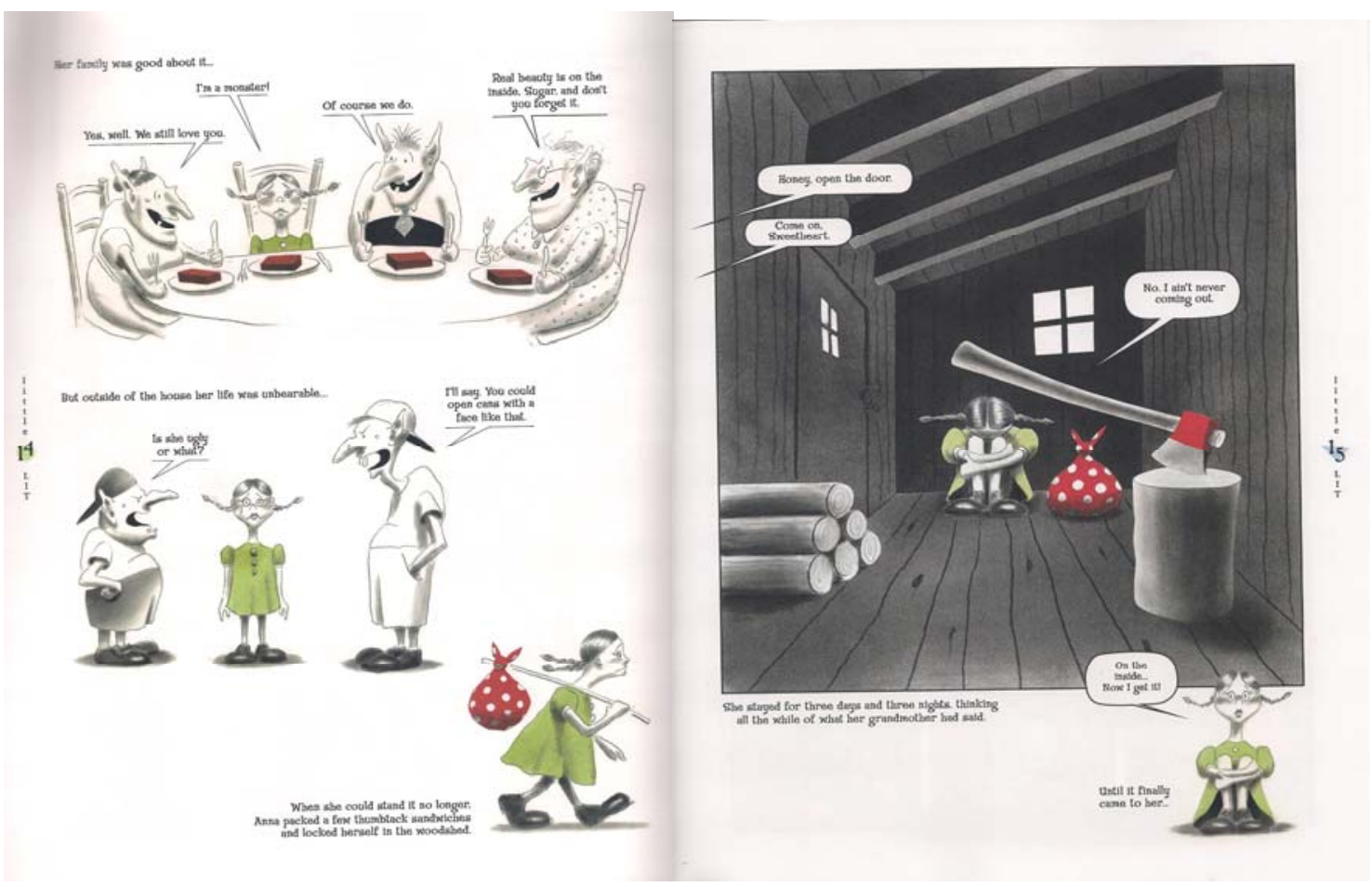

Figura 3. Pretty Ugly

La historieta de Davis Sedaris e Ian Falconer se llama Pretty Ugly. El cómic narra la historia de una niña ogro que de tanto poner gestos de burla se convierte, muy a su pesar, en una niña preciosa. Pese a los intentos de su familia para que la pequeña recobre su aspecto natural, Anna continúa con su aspecto transformado en alguien que no desea, de modo que decide marcharse de casa y esconderse del mundo que la rechaza. En ese punto, la niña se encierra durante tres días y tres noches en una casa del bosque, como vemos en la segunda página del ejemplo. Ese encierro de tres días y tres noches se representa en una única viñeta enmarcada, casi a toda página. La pausa creada a partir del detenimiento de la secuencia de viñetas con una viñeta casi a toda página, es interrumpida cuando la niña encuentra la solución a su problema. Ese “darse cuenta” se representa en la página con una imagen de la niña fuera del marco y mucho menor que la viñeta que marca la pausa. Este recurso último es un punto de fuga, crea expectación con respecto a lo que viene a continuación e invita, como tal, a pasar página. 
Resumen: El resumen se caracteriza por una longitud del relato relativamente menor que la que ocupa el tiempo de la historia y se supone una aceleración de lo acontecido.

Un ejemplo de esta aceleración podemos apreciarla en la historieta de Lorenzo Mattoti The Two Hunchbacks. En ella, dos jorobados dialogan sobre su mala suerte, hasta que uno de ellos logra, después de un viaje y un poco de magia, que desparezca su joroba. Cuando el afortunado vuelve con su compañero y le cuenta cómo consiguió deshacerse del lastre -como el lector ya lo conoce porque lo ha leído en una página anterior-, Mattoti decide comenzar el relato en el bocadillo, a modo de resumen.
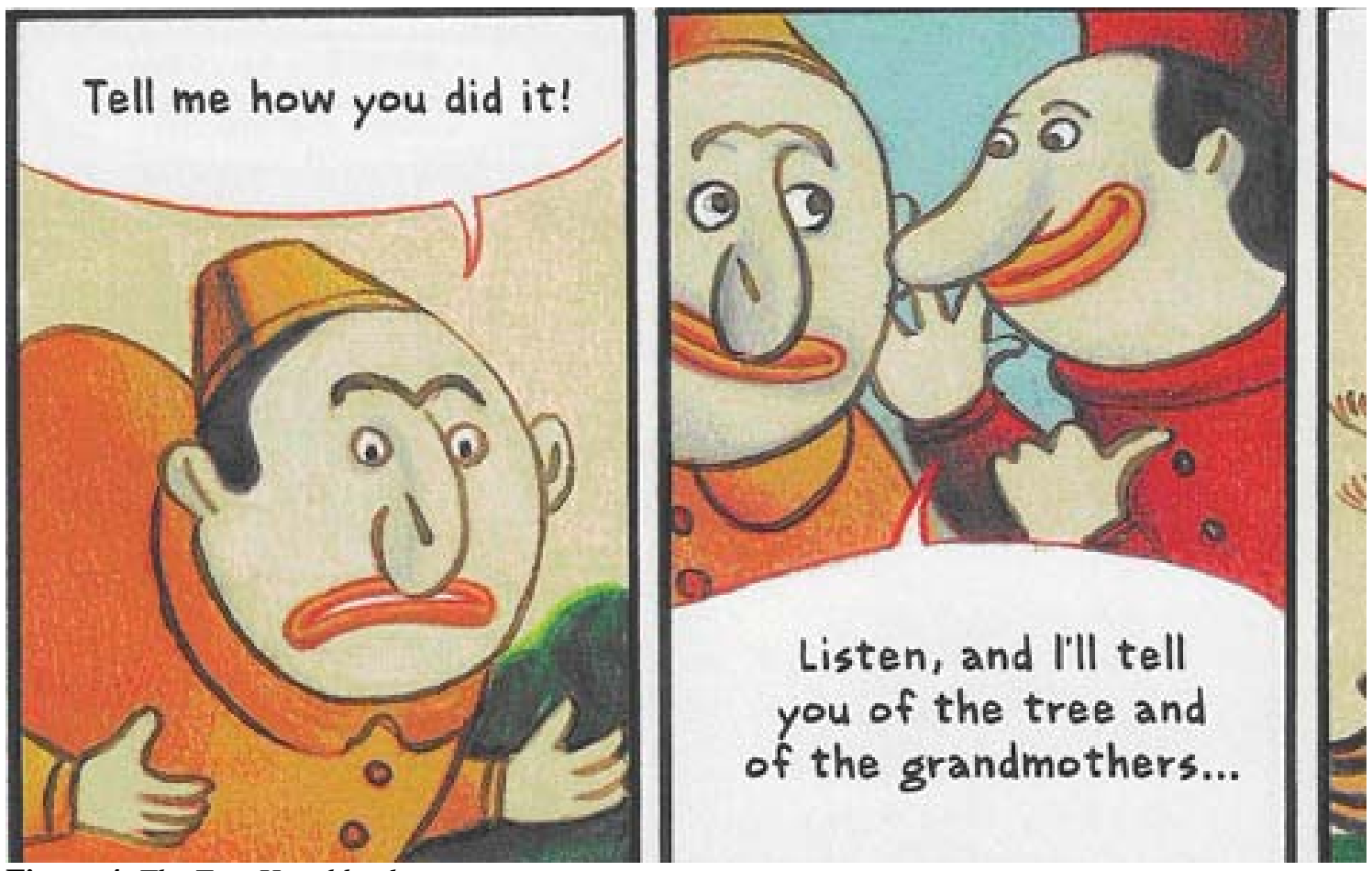

Figura 4. The Two Hunchbacks

Elipsis: La elipsis es la forma máxima de aceleración. Es una duración diegética que no se ve reflejada en el relato o que sólo se insinúa; un tiempo que pasa en la historia pero que se obvia al lector.

Humpty Trouble de William Joyce es un ejemplo, entre muchos, del manejo de la elipsis con la intención de acelerar la acción en caso de que se necesite. Cuando Myron y Ethel Orbly deciden marchar de casa para socorrer a Humpty, un huevo en problemas, se montan en su globo y viajan durante trece días. A pesar de su duración temporal, esos trece días están condensados en una única viñeta, contenida en una más grande, en la que vemos al huevo roto y a la pareja preocupada. 


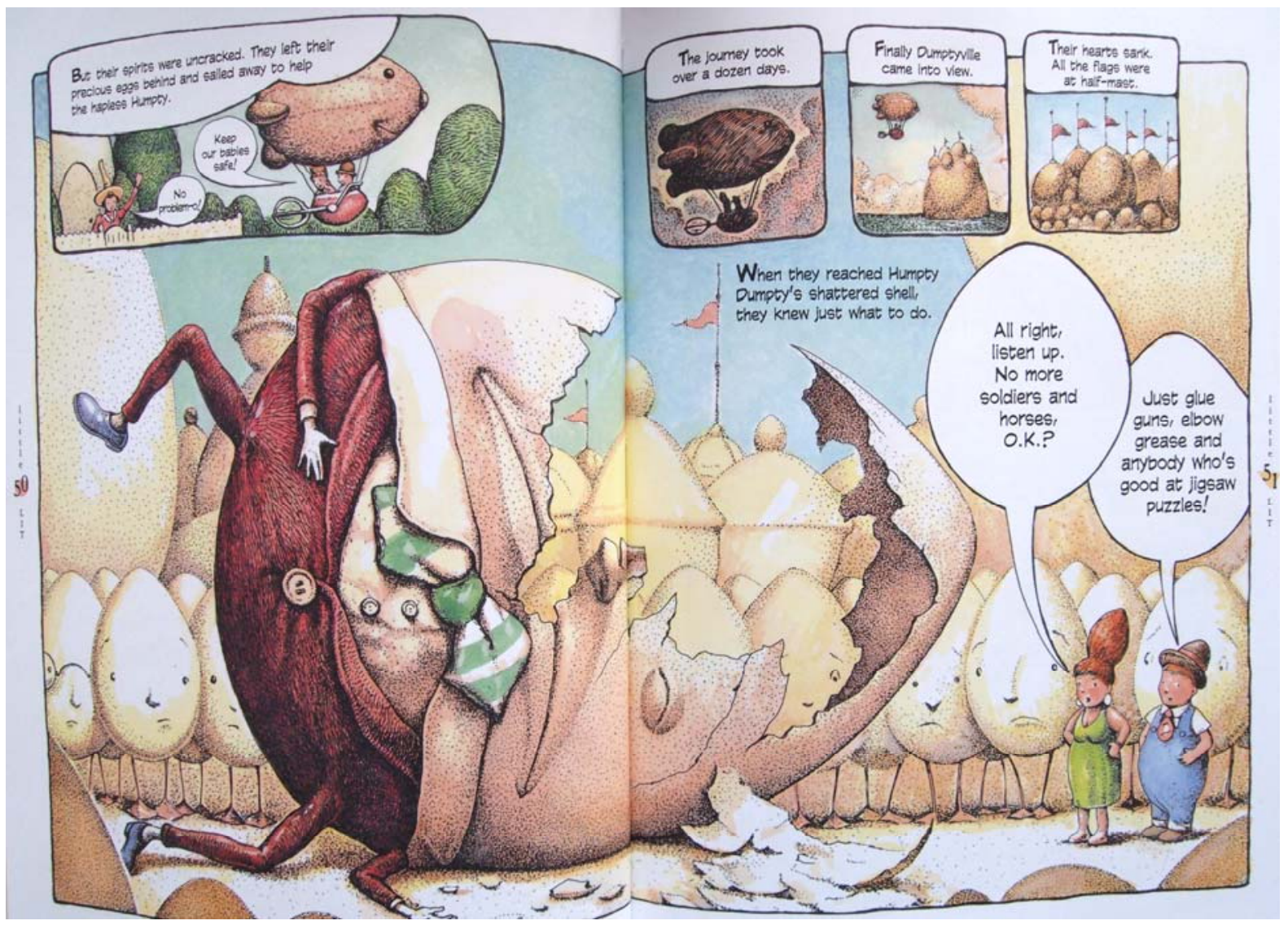

Figura 5. Humpty Trouble

La elipsis, según Genette, puede ser explícita si en el enunciado del narrador conocemos su duración concreta, como en el ejemplo anterior (“El viaje les llevó unos doce días”), o implícita cuando podemos inferir el paso del tiempo aunque no se indique expresamente.

Para completar el cuadro, Seymour Chatman añade un quinto tipo de distorsión de velocidad a las de Genette. El autor lo llama stretch o alargamiento, y se refiere los fragmentos en que el tiempo del discurso es más extenso que el tiempo de la historia. Este recurso se emplea a menudo en espacios de ensoñación de alguno de los personajes de la historia. 


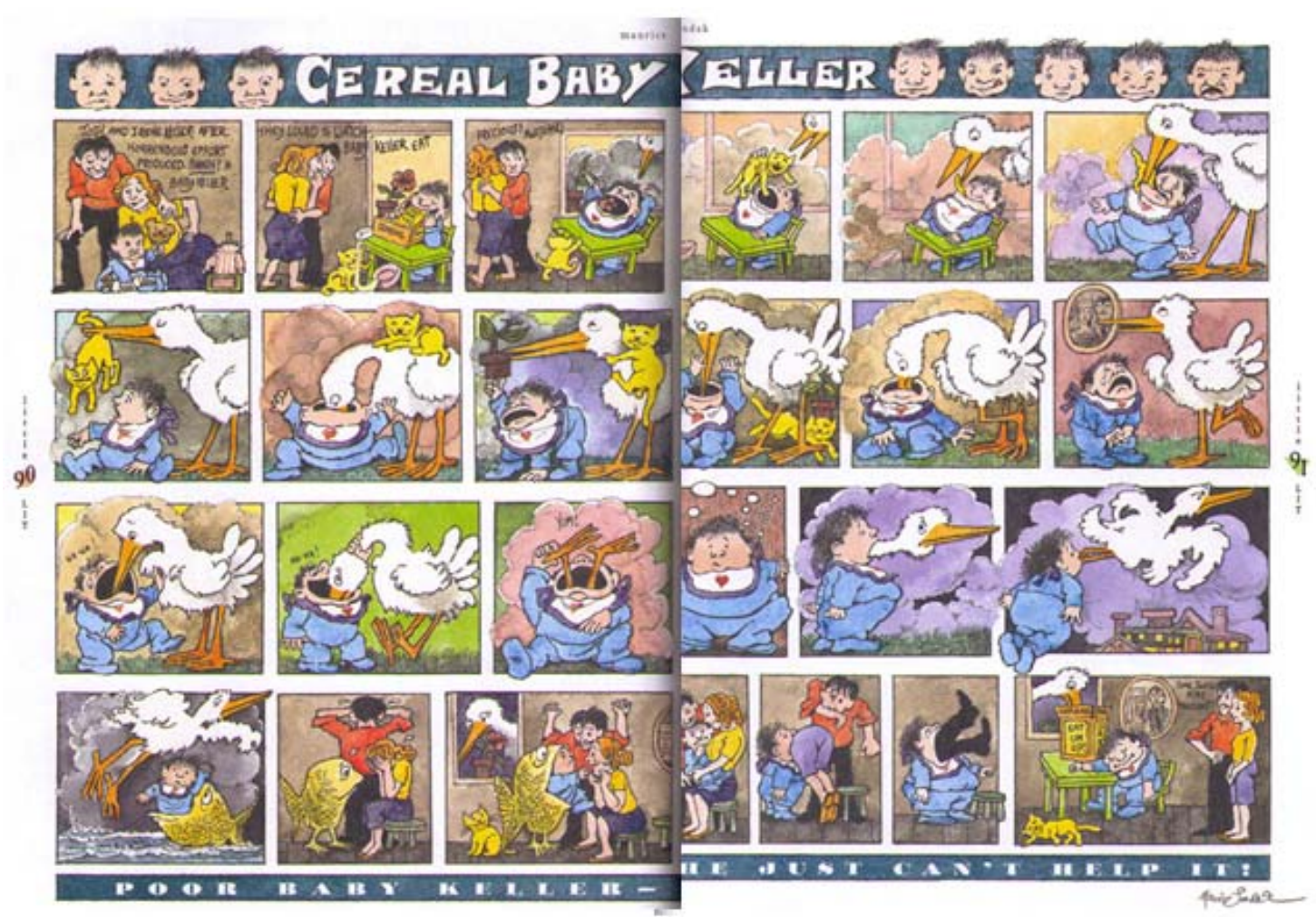

Figura 6. Cereal Baby

\section{Distorsiones de frecuencia ${ }^{3}$}

La frecuencia narrativa se refiere a las relaciones de frecuencia (de repetición) entre los hechos sucedidos y los hechos narrados. Las posibilidades de frecuencia pueden reducirse a los cuatro tipos que recogen un acontecimiento repetido o no, o un enunciado repetido o no.

Relato Singulativo: Se narra una vez lo que ha ocurrido una vez en el nivel de la historia $(1 \mathrm{~d} / 1 \mathrm{~h})$. 


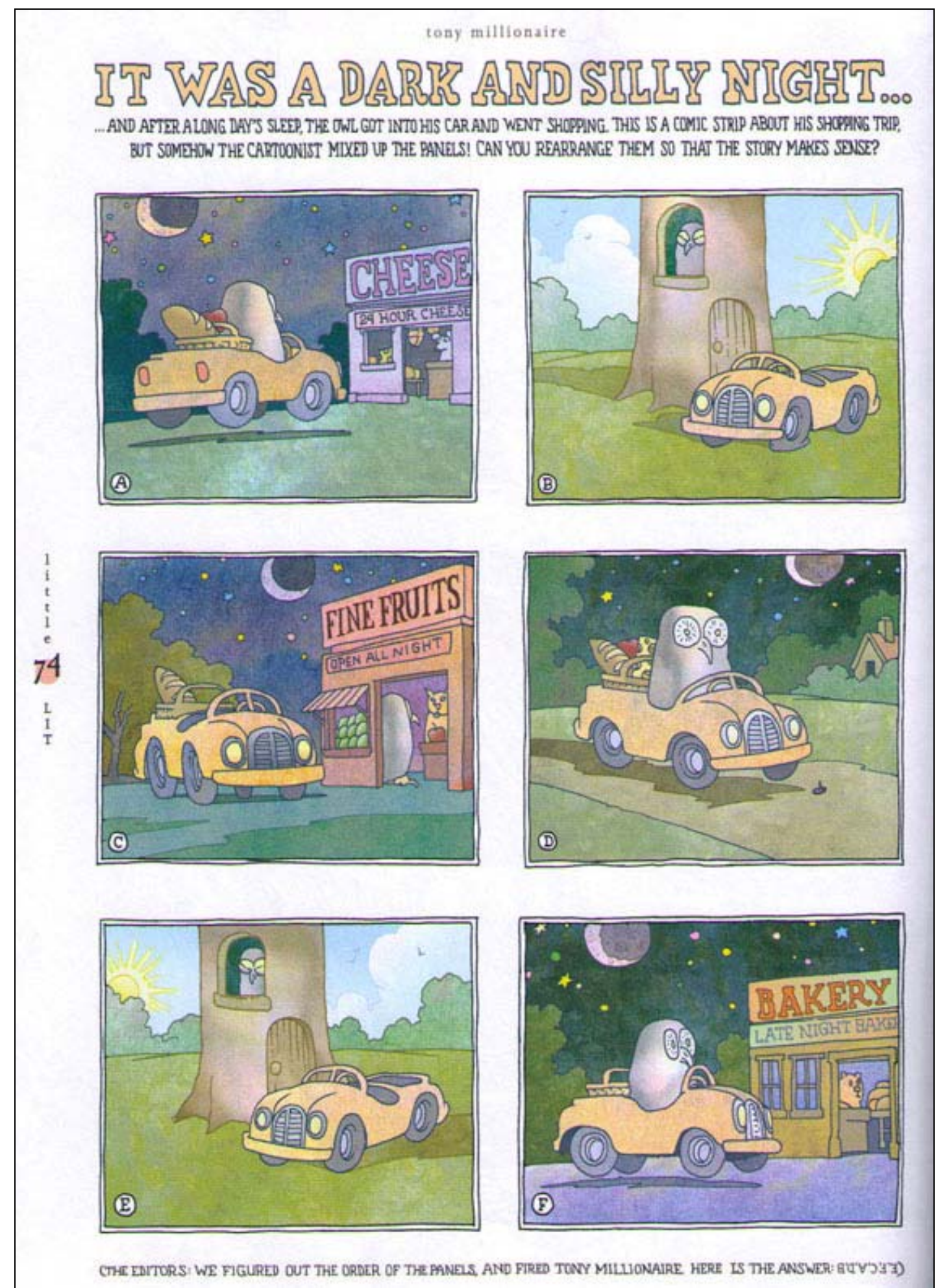

Figura 7. It was a dark and silly night

La historieta que comentamos tiene como autor y dibujante a Tony Millionaire y pertenece al monográfico, dentro del volumen analizado, que se titula It was a Strange and Silly Night. Este cómic tiene la peculiaridad de ocupar una única página pero en ella las viñetas están desordenadas. De modo que una historia tan sencilla como la de un búho que sale a hacer su compra por la noche, en la que se narra una vez lo que ha 
ocurrido a nivel de la historia una vez, se convierte en un ejercicio formal y un juego a nivel de discurso que pocas veces se aprecia en cualquier otro tipo de narrativas, aunque sean infantiles.

Relato Singulativo anafórico: Se narra un número de veces lo que ha ocurrido un número de veces en la historia (nd/ nh).

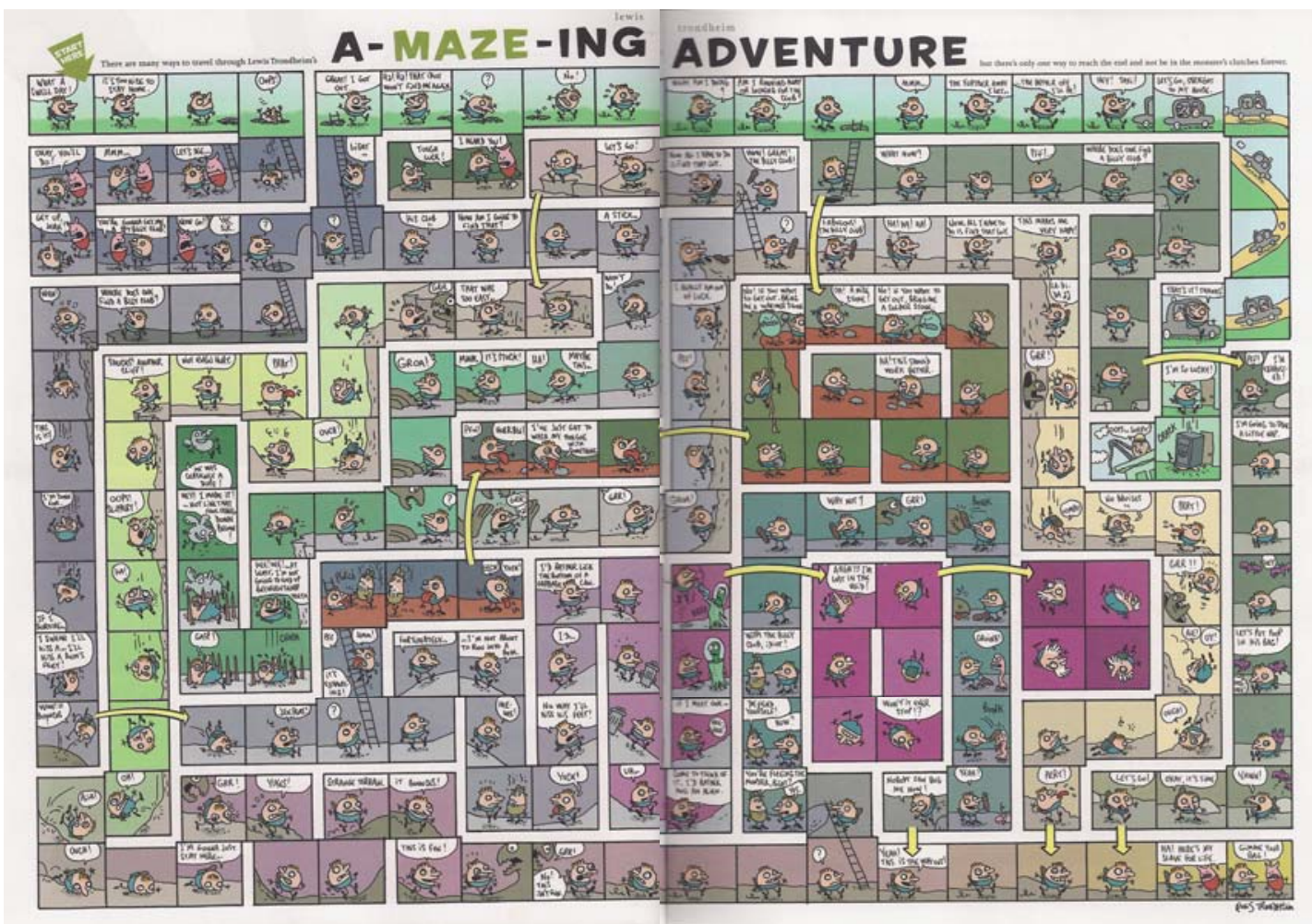

Figura 8. A-maze-ing Adventure

Lewis Trondheim es uno de los más destacados representantes de la Nouvelle Bande Dessinée. En A-maze-ing Adventure lleva a cabo un juego formal en el que esta segunda distorsión de frecuencia queda perfectamente ejemplificada. El protagonista de su historieta tiene la posibilidad de caminar por distintas vías y es el lector, en este caso, quien decide el camino que debe seguir. Al estilo de aquellas novelas juveniles en las que el lector decidía su propia aventura, Trondheim cuenta un número de veces, en su discurso, aquello que ha sucedido un número de veces también en la historia.

A-ma-zing Adverture presenta otra peculiaridad, y es la idea de simultaneidad, es decir, acciones que están teniendo lugar en el mismo lapso de tiempo, donde cada secuencia se distingue de la anterior por el color de los fondos de las viñetas, por su forma y yuxtaposición dentro de la página. 
Relato Iterativo: se narra varias veces lo que, en realidad, ha ocurrido una sola vez a nivel de la historia (nd/1h). Este fenómeno puede que se dé en las distintas versiones que se llevan a cabo de los cuentos de hadas en distintas narrativas. En estos casos, existe una historia base que recoge un autor del folclore y que se reproduce en variantes, de diferente autoría, a posteriori.

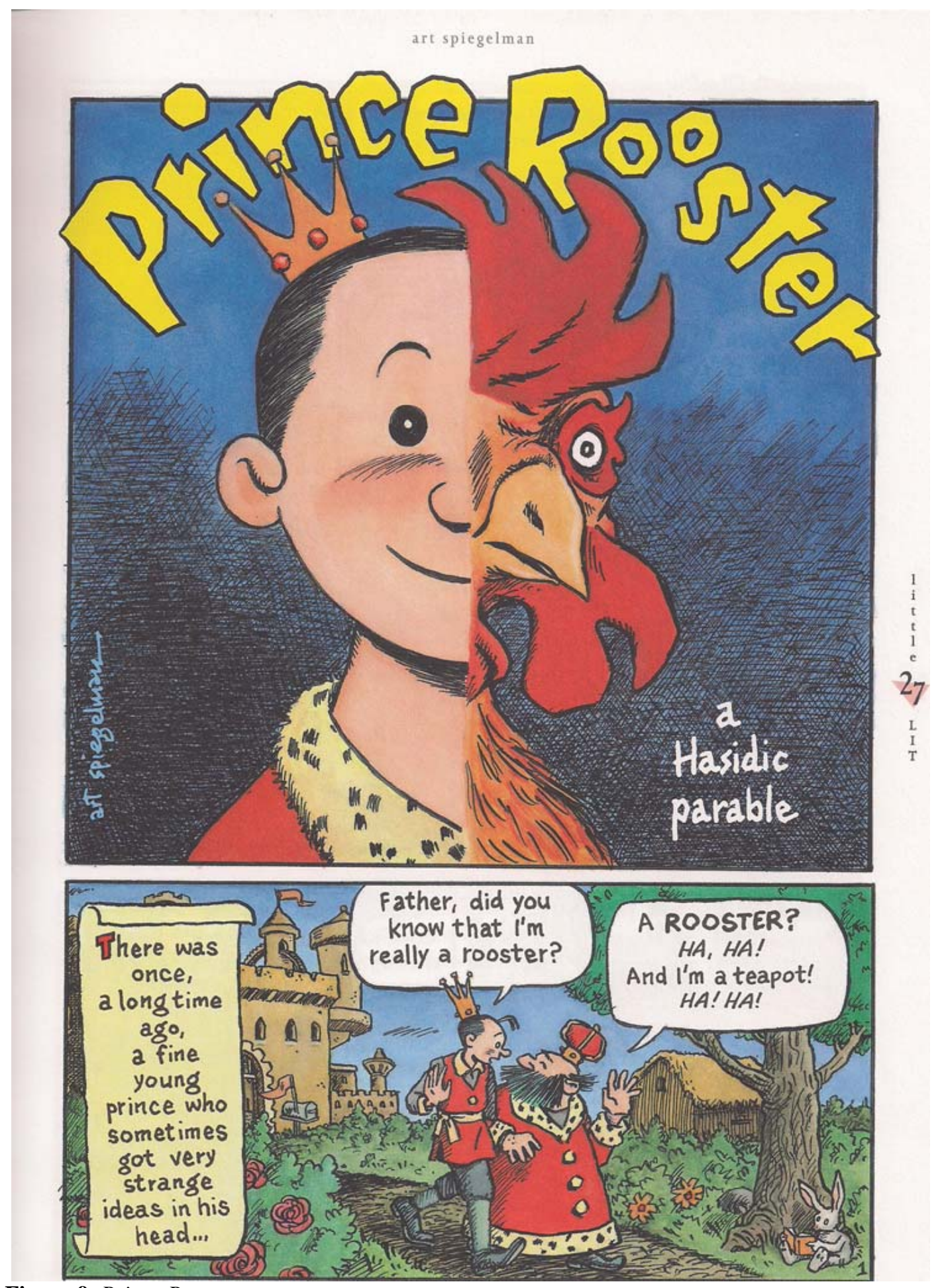

Figura 9. Prince Rooster 
Si ése es el caso, si tenemos una historia base que se cuenta de maneras distintas, en diferentes medios de expresión, ¿estaríamos hablando de relatos iterativos? Según esta definición, Big Fat Little Lit contendría varios ejemplos, todas las versiones que aquí se hacen de los cuentos de hadas.

Relato Repetitivo: se narra una vez lo que ha ocurrido en el discurso un número de veces $(1 \mathrm{~d} / \mathrm{nd})$.
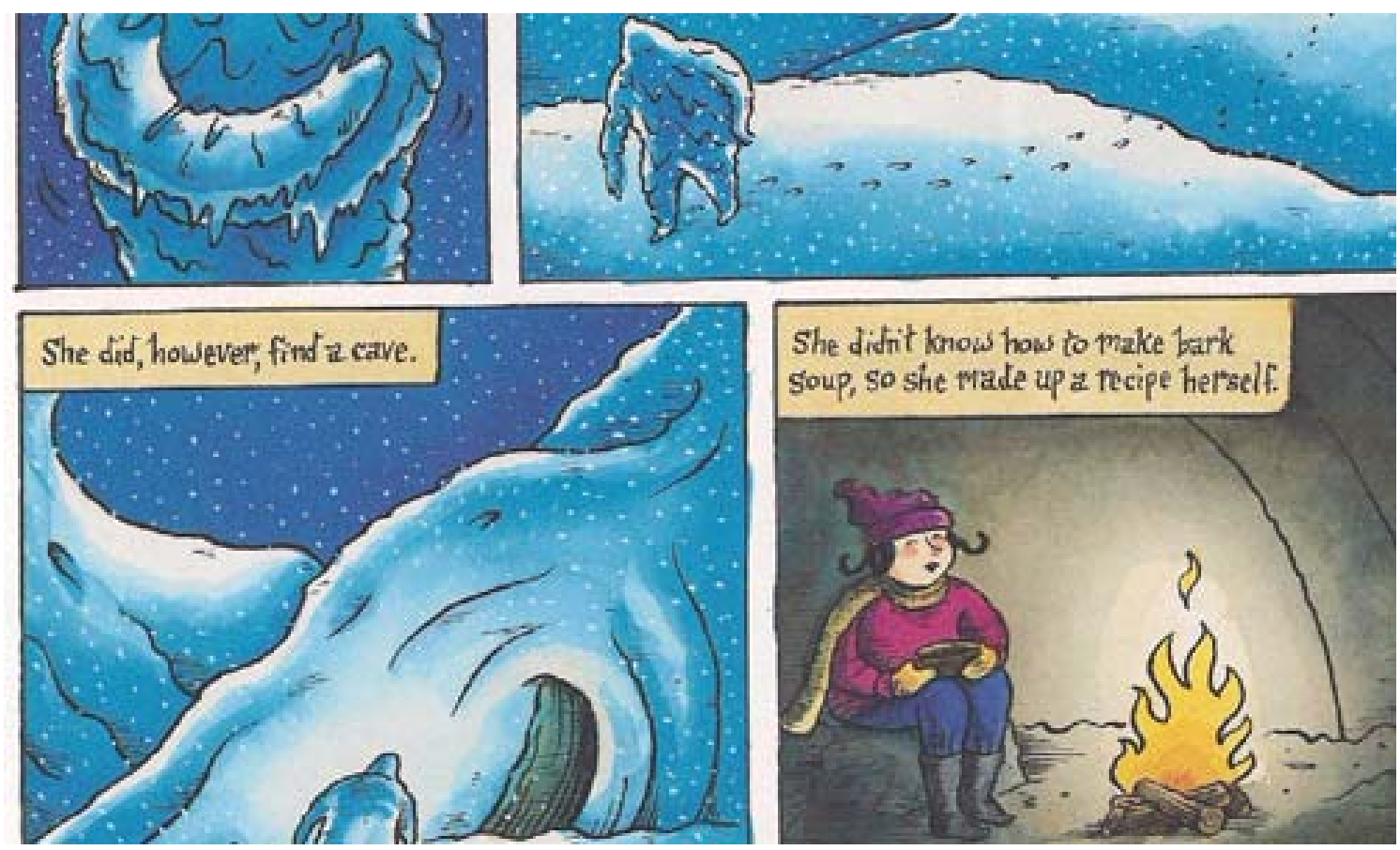

Figura 10. It was a strange and silly night

El siguiente relato, como ocurre en tantos otros dentro del corpus de la literatura infantil, da muestra del esquema que enunciamos. Por lo general se trata de historias circulares en su planteamiento, desarrollo y desenlace. En este último punto, suele haber algún indicio que avisa al lector de que la historia puede que se repita o se repetirá seguro en un tiempo futuro.

La niña protagonista del relato gráfico que utilizamos como ejemplo, se siente atraída por el personaje del Yeti -a quien cree ver a través de la ventana de su casa- y decide salir por la noche en su busca. Debido al tiempo que pasa fuera buscándole, al frío y a la nieve, finalmente es ella la que queda convertida en el monstruo. Durante la narración conocemos a otros personajes que, tanto en el pasado como en el futuro, pasaron o pasarán por la misma situación. De modo que la historia cuenta la transformación de una niña en Yeti, aunque se da a entender que eso mismo ya le ha sucedido a otro de los personajes y puede que le suceda más tarde a un tercero. 
Probablemente, el cuento continuará en un bucle sin fin de niños que, por curiosos, acaban convertidos en monstruos nómadas nevados.

\section{Un estudio sobre el tiempo narrativo en el cómic ficcional infantil}

El presente estudio tiene de peculiar no sólo la elección de un corpus marginal, sino que éste se concibe para un lector infantil. Los trabajos de Teresa Colomer (1998) y María Cecilia Silva-Díaz (2005) relativos a la formación del lector literario o a los álbumes metaficcionales, así como las investigaciones de Gemma Lluch $(2003,2006)$ que tienen a las narraciones audiovisuales como centro de estudio, han servido como referentes y punto de partida para la formulación de algunas hipótesis en el tratamiento del tiempo del corpus seleccionado. Los estudios de estas tres investigadoras nutren con su experiencia, en el ámbito de la narrativa para niños y jóvenes, algunas de nuestras presunciones a la hora de abordar el presente análisis, así como nos permiten establecer conexiones con el modo en que la narrativa se ejecuta en la historieta en comparación con otras obras ficcionales destinadas al mismo público lector.

El estudio del tiempo en la literatura infantil ha sido, en su caso, un elemento más de análisis dentro de un marco mucho más amplio que acoge otros elementos del discurso y de la historia, al igual que su recepción. No obstante, las conclusiones de sus investigaciones sobre cómo algunas producciones infantiles y juveniles adquieren rasgos propios de la cultura en que se desarrollan (del mismo modo que se ven influidas por las producciones culturales coetáneas concebidas para adultos) han podido apreciarse también en el transcurso del presente trabajo.

En este contexto, el tiempo se ve afectado dentro de sus producciones, como en el caso de la historieta, que si bien tiene sus propios códigos y mecanismos de ejecución, comparte con el libro álbum, el cine y la literatura -en general con las narrativas actuales- ese carácter ecléctico y fragmentario propio de la época que vivimos. La historieta infantil también sufre un proceso de complejidad creciente de sus estructuras y contenido y se aleja, desde los años noventa, incluso, de los géneros temáticos puros establecidos, de lecturas más previsibles, en favor del crecimiento lector de un público más exigente, preparado y global que antaño. Este lector implícito no se define, en última instancia, por su edad. Muy al contario, en el caso de la historieta, como ocurre en otras narraciones gráficas, su sofisticación tiene en cuenta la posibilidad de desarrollo de sus capacidades lectoras, que se ven afectadas por el 
contexto social y cultural que lo encuadran y las producciones culturales que allí tienen lugar.

Quisiéramos, entonces, destacar que el lector implícito al que estas obras se dirigen se parece mucho a ellas porque pertenece a "una sociedad postindustrial, alfabetizada y está familiarizado con los sistemas audiovisuales que se incorporan a las corrientes literarias de su tiempo" (Colomer, 1998: 144). Estudiamos, por tanto, una obra ecléctica y cosmopolita creada a partir de elementos de distintas culturas que inventa un nuevo referente cultural, imponiendo unos criterios únicos creados desde culturas diversas (Lluch, 2006), que será recibida por un lector a futuro con esas mismas características.

\section{Conclusiones del estudio}

El análisis del tiempo de los cómics infantiles parte del interés por indagar en el conocimiento de los mecanismos internos de un medio de expresión que consideramos necesario para la construcción del itinerario lector del niño. El tiempo es el elemento intratextual elegido por ser un componente estructural de primer orden en cualquier medio narrativo y por emularse en el cómic, en ocasiones, de manera sofisticada para un lector, en principio, poco experimentado.

1. Sobre cómo funciona el tiempo en la relación texto e imagen: Al lo largo de la investigación, observamos que la forma en que el cómic formula el paso del tiempo se ve reflejada en la palabra, pero también, y de manera pormenorizada, en la imagen; que cuando no existe narrador al uso, la voz narrativa se releva en los diálogos de los personajes que, junto a las viñetas y su yuxtaposición en la página, marcan el orden temporal del discurso. Encontramos que estos espacios donde se desarrolla la imagen son fragmentos de tiempo que se colocan en secuencia para proporcionar verosimilitud a la narración de la acción.

Estas narraciones dirigidas al lector infantil se caracterizan, en relación al estudio de su elemento temporal, por construir relatos singulativos (1d/1h) e iterativos (nd/1h), sin muchas anacronías; con un desarrollo importante de la experimentación en las distorsiones de velocidad, cuya voz narrativa se intercala entre la tercera persona de un narrador externo (su ausencia), los diálogos de los personajes y la imagen narrativa.

La palabra en las historietas que analizamos tiene la función de concretar, aclarar y ubicar al lector mientras que la imagen se permite el juego, la evocación y la libertad dentro de una estructura preestablecida. Hemos observado, por tanto, licencias lúdicas y 
poéticas en historias que juegan con el desorden, la elipsis, la pausa o la simultaneidad, precisamente por estar dotadas de una estructura sólida que les permite, en estos casos, la demanda de la participación lectora.

2. Sobre el tiempo narrativo en los cómics infantiles y sobre los recursos concretos utilizados en su expresión: Si bien es cierto que la mayoría de los textos analizados en este corpus concreto, con respecto al tiempo, siguen una progresión lineal -la ordenación de sus acciones en el discurso sigue la de la historia-, eso no significa que el discurso de las historietas resulte pobre ni simplista.

Los autores de dichos ejemplos dan cuenta de las posibilidades que ofrece el cómic a la hora de expresar simultaneidad de acciones y de cómo los constantes vacíos temporales, que pudieran dificultar la comprensión de la obra, se resuelven gracias a la concreción que aporta la palabra en títulos, marcadores temporales, diálogos etc.

Queremos resaltar, de la misma manera, que aunque la elección más extendida por parte de los creadores a la hora de narrar sea el tiempo pasado por un narrador heterodiegético, es decir, alguien que cuenta la historia desde fuera del mundo del relato, generalmente en tercera persona, éste recrea un espacio de posibilidades que afecta tanto al contenido como a la forma. Estas historias pasadas, que distan del tiempo en el que la obra se concibe, beben de otras narraciones que llegan del folclore como los cuentos maravillosos y los cuentos de hadas y en el cómic se renuevan.

Por contra, sabiendo que las narraciones ulteriores suponen un 51\% dentro del corpus elegido, resulta curioso reparar en la combinación constante de diferentes tiempos verbales que la voz narrativa expresa a la vez en las didascalias destinadas al narrador y en los diálogos que se establecen entre los personajes dentro los bocadillos. Tiempos presentes, pasados y futuros se dan cita en las cajas y globos de texto, donde, de pronto, el cómic, el cine y el teatro se parecen.

Llegados a este punto concluimos, sin lugar a dudas, que el cómic es, en esencia $\mathrm{y}$ en su discurso, un medio que expresa sobre todo simultaneidad y que esa característica le distingue de otras formas narrativas. En este sentido la viñeta puede expresar el paso del tiempo de la narración, igual que puede expresar su pausa; o la coincidencia temporal de acciones varias que tienen relación dentro de la misma página.

De hecho, de entre todas las distorsiones de tiempo que hemos analizado, son las de velocidad las más explotadas para emular ese orden temporal de historia y discurso, y la elipsis, dentro de ellas, la más constante. La elipsis, la pausa, el resumen y la escena ofrecen una narración fraccionada de aceleraciones y desaceleraciones, en la que 
el desarrollo de la historia depende de las incursiones del lector y su participación en la construcción de significados se torna mucho más activa; incluso en un sentido físico, cuando al lector no sólo se le pide que descodifique y comprenda sino que interprete, que ordene, que busque, que localice o que elija de entre las muchas historias que se le presentan en un mismo espacio.

Como sucede en otros libros infantiles, la elección del orden temporal lineal parece ser la condición enunciativa más respetada en la producción de cómics para niños. De modo que las anacronías sólo suelen ocurrir cuando se necesitan, por ejemplo, para explicar sucesos ocurridos con anterioridad que afecten al contenido y comprensión de la historia o para avisar de acontecimientos futuros que creen cierta expectación. Sin embargo, así como las complicaciones en cuanto a la enunciación del orden temporal dependen, según Colomer (1998), de la edad del destinatario, el cómic infantil atiende más bien a la capacidad que éste haya desarrollado para la reconstrucción de una narrativa fragmentada, que obliga a esos movimientos de anticipación y retroceso y que tiene que ver, por tanto, con su bagaje lector del medio.

Diríamos entonces, al hilo de las conclusiones del estudio de Colomer (1998) en sobre la formación del lector literario, que en el caso de la historieta el lector implícito no se define por su edad sino por sus capacidades. Por tanto, la publicación que se estudia en el presente trabajo está concebida para niños que tienen un bagaje de lecturas que al menos acoge la recepción de cuentos de hadas, cuentos maravillosos y primeras narraciones gráficas. Esos niños pudieran tener de seis a diez años y su lectura de la obra en cuestión cabe que sea simple o compleja, dependiendo de su destreza y capacidad de interpretar esos mundo polifónicos, esa simultaneidad de tiempos, de acciones y de informaciones fragmentadas que tienen lugar en este espacio.

Casi al final de este periplo, una vez analizado el tiempo intratextual, observamos que si bien es cierto que se tiene cuidado en la elección del orden cronológico del discurso, los autores no renuncian a las oportunidades de experimentación que brindan otras distorsiones temporales. De hecho, ni siquiera se perciben diferencias importantes con las obras que ellos mismos crean para adultos en el uso del color, la forma, la textura, la dimensión o el movimiento, del mismo modo que tampoco se excluyen las distorsiones de velocidad y frecuencia. Muy al contrario, pueden leerse ejemplos de gran valentía, precisamente por ser textos destinados a la infancia. El receptor, en este punto, se situará ante una dimensión estética de peso con la 
que irá construyendo su imaginario, gusto y bagaje artístico a la vez que se le cuenta una historia.

Así como se tiene en cuenta el uso de un lenguaje sencillo y una temática acorde a los intereses del lector objeto a la hora de dar forma a la historia, pareciera que el propio medio se preste a la experimentación, al guiño y al deseo de complicidad en la construcción de los significados de esa historia y en su discurso.

Las conclusiones del presente estudio se ultiman, por tanto, muy en la línea de las investigaciones que han servido para trazar su marco teórico. El estudio pormenorizado del orden temporal de historia y discurso, de los tiempos verbales que emplea la voz narrativa, del tiempo en la recepción y duración de la historieta actual para niños, muestra un aumento del requerimiento en cuanto a la participación lectora para completar el sentido último de los textos, un aumento, en consecuencia, de la complejidad de un discurso fragmentario y una tendencia hacia la globalización narrativa tanto en el fondo como en la forma en que se presentan. Hemos constatado, a través del estudio, la manera en que estos órdenes temporales ponen en relación aspectos importantes que nos llevan a comprender mejor el medio que estudiamos, así como a redefinirlo desde perspectivas narratológicas en el ámbito de las producciones ficcionales y artísticas para niños y jóvenes.

Es tiempo ahora del último tiempo, el de la lectura. Este tiempo extratextual se torna lento y subjetivo, se adapta a las necesidades y curiosidad del lector que pasa las páginas a su propio ritmo. Pareciera incluso similar a ese tiempo de la imaginación que protagoniza el personaje y que se dilata en el discurso de los cómics. Un tiempo de ensoñación, de soledad, de preguntas; un tiempo para el juego y la invención.

Este es, sin duda, el tiempo más importante -completamente distinto dependiendo del medio narrativo-: el tiempo de la lectura, sin el cual los tiempos que habitan en el interior del texto nunca existirían.

\section{Referencias bibliográficas}

Chatman, S. (1990). Historia y discurso: estructura narrativa en la novela y en el cine. Buenos Aires: Taurus.

Chatman, S. (1980). What novels can do that films can't (and vice versa). On Narrative. Chicago: The University of Chicago Press.

Colomer, T. (1998). La formación del lector literario. Madrid: Fundación Germán Sánchez Ruipérez.

Eisner, W. (1996). El cómic y el arte secuencial. Barcelona: Norma.

Genette, G. (1998). Nuevo discurso del relato. Madrid: Cátedra. 
Genette, G. (1972). Figuras III. Madrid: Lumen.

Groensteen, T. (2007). The System of comics. Jackson: University Press of Mississippi. Guiral, A. (2007). Del tebeo al manga: una historia de los cómics. Barcelona: Panini. Harvey, R.C. (2011). Bill Blackbeard, the man who saved comics, Death at 84.The Comic Journal. Descargado el 31 de diciembre de 2011 de: http://www.tcj.com/bill-blackbeard-1926-2011.

Kunzle, D. (1990). The nineteenth century. The history of the comic strip 2. Berkeley: University of California Press.

McCloud, S. (2005). Entender el cómic. El arte invisible. Bilbao: Astiberri.

Spiegelman, A., \& Mouly, F. (Eds.) (2006). Big fat little lit. New York, NY: Puffin Books.

Muro, M. Á. (2004). Análisis e interpretación del cómic. Ensayo de metodología semiótica. Logroño: Universidad de la Rioja.

Lluch, G. (2003). Análisis de narrativas infantiles y juveniles. Cuenca: Universidad de Castilla-la Mancha.

Lluch, G. (2006). Star Wars: una manera clásica de contar aventuras. Madrid: Biblioteca Cervantes Virtual.

Silva-Díaz, M. C. (2005). Libros que enseñan a leer: álbumes metaficcionales y conocimiento literario. Tesis doctoral. Descargado el 7 de octubre de 2011 de: http://www.tesisenxarxa.net/TDX-0621106-000248/

\footnotetext{
${ }^{1}$ Las distorsiones de orden sólo suponen un 13\% del total de historietas analizadas. Sin embargo, existen ejemplos que, relacionados con el juego, expresan constantes acciones simultáneas dentro de la misma página. Este recurso característico del cómic, de alguna manera, altera la percepción del orden de la historia que se está narrando.

${ }^{2}$ Las distorsiones de velocidad se dan en todos los títulos que conforman el corpus empleando para ello distintos recursos.

${ }^{3}$ El relato singulativo supone un $43,3 \%$, el relato singulativo anafórico un $10 \%$, el relato iterativo supone un $30 \%$ y el relato repetitivo supone un $16,7 \%$ del total de los ejemplos analizados.
}

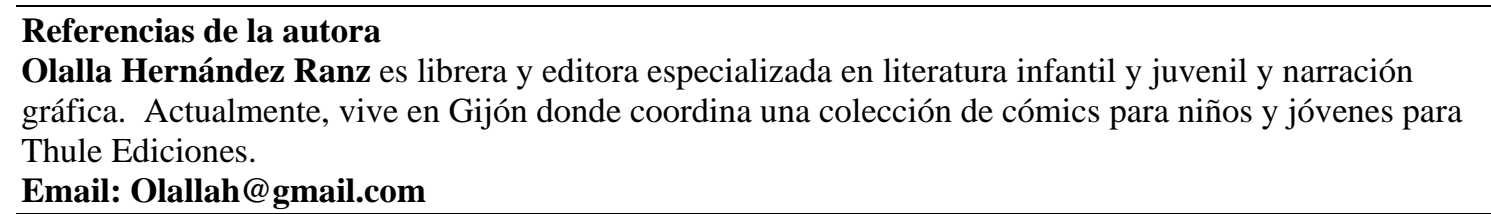

Para citar este artículo:

Hernández Ranz, O. (2012). Grande y gruesa pequeña literatura. Bellaterra Journal of Teaching \& Learning Language \& Literature, 5(1), 39-59. 